\title{
FORMAL DEFINITION OF BUSINESS RULES BY GRAMMAR SYSTEMS
}

\author{
Hypský Roman, Kreslíková Jitka, Zámečníková Eva
}

\begin{abstract}
This paper discusses the formalization of business rules using grammar systems. At the beginning are specified business rules and grammar systems. Then it is described the application of business rules by grammar systems. Finally, the results are evaluated and future development is suggested.
\end{abstract}

Keywords - business rule, grammar system, formalization

\section{Introduction}

Business rules are currently very popular and sought-after concept in environment of organizations and businesses. More and more organizations are starting to use and work with business rules management. The area of our research is the identification and categorization of business rules and their subsequent formalization through methods of modern theoretical computer science. We focused mainly on use of grammar systems, the most famous of these include Cooperating distributed grammar systems (further CD grammar systems) and Parallel communicating grammar systems (further PC grammar systems). But we don't forget to mention other possible methods of modern theoretical computer science. If it was successful to formalize the business rules using grammar systems, It would greatly facilitate their subsequent application in business processes.

\section{Definitions}

In this chapter will be described basic formal models and detected theory.

\section{A. Business Rules}

As the name suggests business rules are a set of rules that enable and partially automate and accelerate the company's decisions in certain business processes. The rules, which we mainly studied, work on the basis of the implication. If it is anything accomplished, then execute something (IF condition THEN action). Therefore this basic version has two parts: Condition and Action (can be seen on figure 1). Business rules can be described by using natural language therefore we need a unified business dictionary. For the recognition of business rules from the simple sentences there exist methods and heuristics. The risk of disambiguation must be eliminated.

Ing. Roman Hypský | doc. RNDr. Jitka Kreslíková, CSc. | Ing. Eva Zámečníková

Brno University of Technology

Czech Republic
They are usually described using BPEL language in practice [3]. Business rules on Figure 1 are written in BPEL notation.

Typical use of these rules is in processes that contain easily automated actions that do not depend on other human interaction or opinion. Rules can be used for example in the banking sector, or for example for determination of the payroll. Here are two examples of business rules in practise:

- If bank client is with bank more than 5 years, no commitments, and has a steady income greater than CZK 20 000, he can automatically get a loan without collateral to CZK 100000

- If the total price of the order is min. CZK 1000, shipping is free.

Main advantages of using business rules in practise are partial automation of processes and saving of relevant resources (time and people) and it's not necessary to change processes, but we can simply add or modify rules. By the introduction of the business rules formalization we also may partly control real processes by adding restrictions upon the of grammar rules. Used business rules can be formalized, and easily implemented using the information system and therefore can be automated [3].

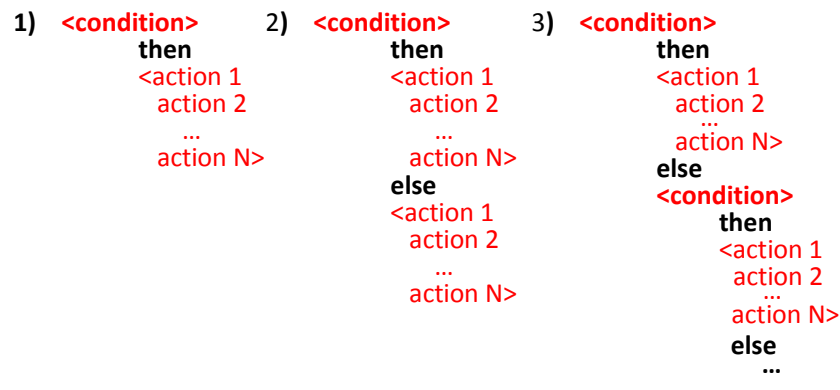

Figure 1. Basic types of Condition and Action Business rules

\section{B. Grammar Systems}

Grammar systems represent a set of grammars working together. If calculation is running on multiple stations, the stations are synchronized using the protocol to produce same language. Compilation at multiple locations is implemented for several reasons. For example because of computational complexity or increase of the generative power. There are two basic types of grammar systems: $C D$ grammar systems and $P C$ grammar systems. 
Proc. of the Second Intl. Conf. on Advances in Information Processing and Communication Technology - IPCT 2015

Copyright $\odot$ Institute of Research Engineers and Doctors, USA .All rights reserved.

ISBN: 978-1-63248-044-6 doi: 10.15224/ 978-1-63248-044-6-74

\section{1) Cooperating Distributed (CD) Grammar Systems}

This is type of sequential grammar systems. This means that individual grammars are alternating during generating sentence form and it proceeds sequentially. All parts have a common sentence form, where each time works just one of the grammars. The transfer of control between grammars is an important element.

CD grammar system is defined as (1), where N, T, S are defined like in standard definition of grammar (alphabet of nonterminals, alphabet of terminals and starting nonterminal respectively). $\mathrm{P}_{1}, \ldots, \mathrm{P}_{\mathrm{n}}$ are sets of rules of each grammar. $\mathrm{N}$ sets a degree of grammar system, where $n \geq 1$.

$$
\Gamma=\left(\mathrm{N}, \mathrm{T}, \mathrm{S}, \mathrm{P}_{1}, \ldots, \mathrm{P}_{\mathrm{n}}\right)
$$

The transfer of control between grammars can be used in several modes ( $\mathrm{t}, *$, k-step, etc.).

\section{2) Parallel Communicating (PC) Grammar} Systems

In comparison with Sequential systems these systems work in parallel. Each grammar has own sentence form, so they can work parallel, each on own sentence form. There are query symbols for replacing sentence form. This grammar system is defined as (2), where $\mathrm{N}$ is alfabet of nonterminals, $\mathrm{T}$ is alfabet of terminals, $K$ is a finite set of query symbols $K=\left\{Q_{1}, \ldots\right.$, $\left.\mathrm{Q}_{\mathrm{n}}\right\}$ and $\left(\mathrm{S}_{1}, \mathrm{P}_{1}\right), \ldots,\left(\mathrm{S}_{\mathrm{n}}, \mathrm{P}_{\mathrm{n}}\right)$ are components of system. Each of them has own starting symbol $\mathrm{S}$.

$$
\Gamma=\left(\mathrm{N}, \mathrm{K}, \mathrm{T},\left(\mathrm{S}_{1}, \mathrm{P}_{1}\right), \ldots,\left(\mathrm{S}_{\mathrm{n}}, \mathrm{P}_{\mathrm{n}}\right)\right)
$$

For our research is the key Centralized PC grammar system as only component $\mathrm{P}_{1}$ has query symbols and it can communicate with other components. Chapters about grammar systems were based on sources [1] and [2].

\section{Idea of Application Business Rules by Grammar Systems}

For cooperation business rules and grammar systems we derived two possible solutions:

- Create business rules to fall into classes for which we have created a model of grammar system.

- Create random rules as we need and for each create a special grammar system.

In this paper we focus mainly on the first mentioned solution.

The idea of the application is as follows. We have simple type of business rule (see figure 1, case 1) and we can perform every action by $\mathrm{CD}$ and $\mathrm{PC}$ grammar system (like on figure 2).
CD Grammar System PC Grammar System (centralized)
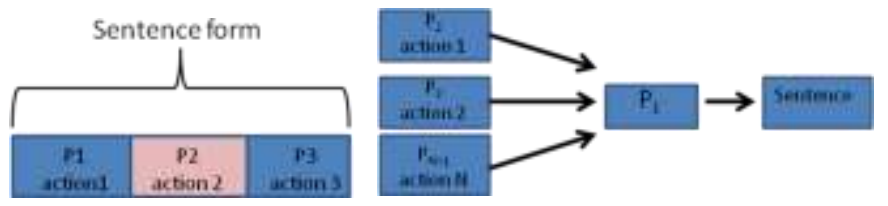

Figure 2. Application of Busines Rules by CD and PC Grammar system

\section{A. Example}

We try to decribe the application on example. Consider business rule Determination of Salary (figure 3). We have CD grammar $\Gamma$ system with two components $\mathrm{P} 1$ and $\mathrm{P} 2$.

$$
\begin{aligned}
& \Gamma=\left(\mathrm{N}, \mathrm{T}, \mathrm{S}, \mathrm{P}_{1}, \mathrm{P}_{2}\right) \\
& \mathrm{N}=\{\mathrm{S}, \mathrm{A}, \mathrm{B}, \mathrm{C}, \mathrm{D},\} ; \\
& \mathrm{T}=\{\mathrm{a}, \mathrm{b}, \mathrm{c}, \mathrm{d}\} ; \\
& \mathrm{S}=\{\mathrm{S}\} ; \\
& \mathrm{P} 1=\{\mathrm{S} \rightarrow \mathrm{S}, \mathrm{S} \rightarrow \mathrm{ABd}, \mathrm{C} \rightarrow \mathrm{A}, \mathrm{D} \rightarrow \mathrm{B}\} \\
& \mathrm{P} 2=\{\mathrm{A} \rightarrow \mathrm{aCb}, \mathrm{B} \rightarrow \mathrm{cD}, \mathrm{A} \rightarrow \mathrm{ab}, \mathrm{B} \rightarrow \mathrm{c}\}
\end{aligned}
$$

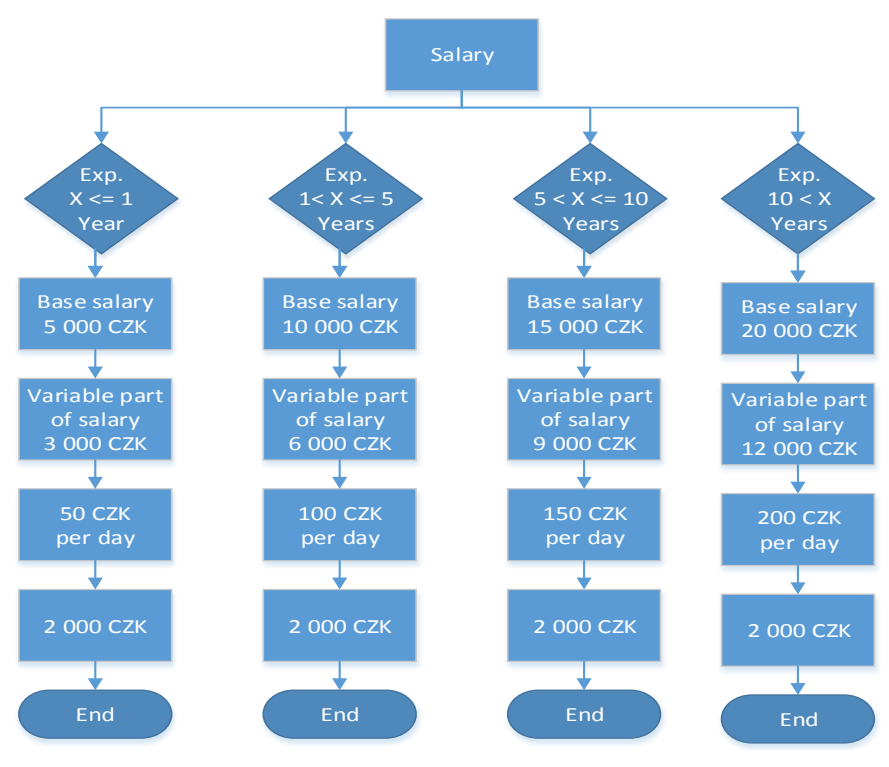

Figure 3. Application of Busines Rules by CD and PC Grammar system

This CD grammar system generates language $L_{=2}\left(a^{n} b^{n} c^{n} d\right.$ : $\mathrm{n} \geq 1$ ) in k-step mode $=2$. Then we must define constants for our example of business rule.

$$
\begin{aligned}
& \mathrm{n}=\text { salary class } \\
& \mathrm{a}=\text { base of salary (typicaly CZK } 5000) \\
& \mathrm{b}=\text { base of meal vouchers (CZK 50) } * \text { days in month } \\
& \mathrm{c}=\text { base of bonuses }=\text { tasks }+ \text { behavior }+ \text { attendance } \\
& \mathrm{d}=\text { bonus (CZK 2000) }
\end{aligned}
$$

Now we can calculate business rule by $\mathrm{CD}$ grammar system $\Gamma$. Calculation for salary of class 2 looks like this: 
Proc. of the Second Intl. Conf. on Advances in Information Processing and Communication Technology - IPCT 2015

Copyright $\odot$ Institute of Research Engineers and Doctors, USA .All rights reserved.

ISBN: 978-1-63248-044-6 doi: 10.15224/ 978-1-63248-044-6-74

$\mathrm{a}^{2} \mathrm{~b}^{2} \mathrm{c}^{2} \mathrm{~d}=5000+5000+(50 \times 30)+(50 \times 30)+(1000+1000+1000)(1$ $000+1000+1000)+2000=21000 \mathrm{CZK}$.

Summary of the application of this example is shown in table 1.

Using the PC grammar system is very similar. We use centralized PC grammar system with three components which produce the same language $\mathrm{L}(\Gamma)=\left\{\mathrm{a}^{\mathrm{n}} \mathrm{b}^{\mathrm{n}} \mathrm{c}^{\mathrm{n}}: \mathrm{n} \geq 1\right\}$.

TABLE I. SUMMARY OF THE APPLICATION BUSINESS RULE DETERMINATION OF SALARY

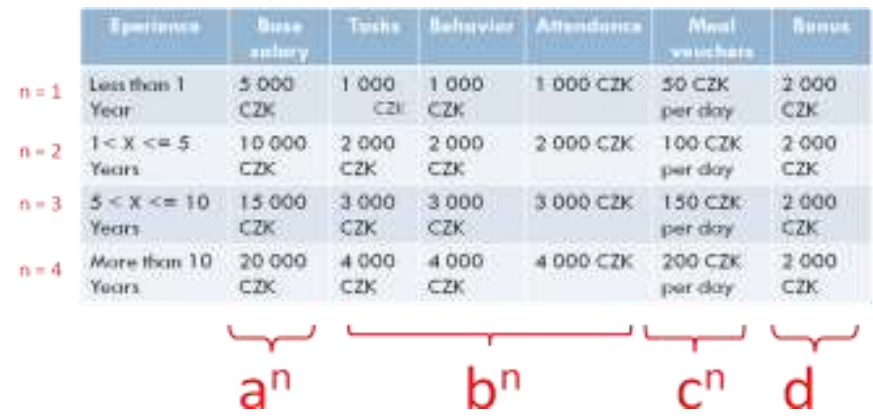

\section{B. Summary of Application}

According to the given example we think that better approach is to create business rules to fall into classes for which we have created a model of grammar system. There exist more types of business rules than the type we discussed (condition - action). For example limitations, etc. we studied only condition - action rules in this paper. For completeness, we would have to study application of the other types of rules. We think that this issue could be a good use of hybrid CD grammar systems. These are systems where every component (action) can have own mode. Using centralized PC grammar systems could also be useful. Every action can be performed independently and component $\mathrm{P}_{1}$ then create final string. This system we can use for application a set of business rules not only for part sof one rule.

\section{Iv. Formalization of Business Rules by Grammar Systems}

Based on the findings obtained during Application business rules by grammar systems we proposed possible process of formalizing business rules. This process consists of three main steps:

- Creation of the business dictionary with all expressions that are used in organization (set of terminal symbols).

- Transformation of business rules from these terminal symbols by special rules (patterns).

- This patterns categorized business rules into the classes which we have model of grammar system for each of these classes.

\section{A. United Dictionary of Organization}

At the first we must create United dictionary of given organization. Terminals of this dictionary can be divided to the sets by their common characteristics. Example individual sets can be as follows:

- $\quad \mathrm{T}_{\text {people }}=\{$ client, employee, boss $\}$

- $\quad \mathrm{T}_{\text {subject }}=\{$ salary, meal_voucher, bonus, experience $\}$

- $\mathrm{T}_{\text {period }}=\{$ year, month, week, day $\}$

- $\quad \mathrm{T}_{\text {money }}=\{$ thousand, voucher, 5 thousands, bonus $2 \mathrm{k}\}$

All terms used in business rules must be included in any of these sets.

\section{B. Patterns}

If we already have created United dictionary of organization, we must create patterns of business rules. Every rule used in the organization must have own pattern. Example of pattern can be as

- If $(<$ Tpeople $><$ Tsubject $><=$ number $<$ Tperiod $>$ ) then

$<$ thousand $\rangle^{\mathrm{n}}\langle\text { voucher }\rangle^{\mathrm{n}}\langle\text { bonus } 2 \mathrm{k}\rangle^{\mathrm{n}}$

- ( client experience $<=1$ year ) then

$5000^{\mathrm{n}} \quad$ voucher $^{\mathrm{n}} \quad 2000^{\mathrm{n}}$

where $\mathrm{n}$ is salary class identified from condition.

\section{Categorization to the Classes}

Finally, we must create grammar system for each pattern. Every pattern is in class which has own model of grammar system. In this case is it grammar system which produces language $L_{=2}\left(a^{n} b^{n} c^{n}: n \geq 1\right)$. This grammar system was mentioned earlier.

\section{v. Decision Management Systems}

One way of practical use of formalization of business rules can be used by companies during creating of decision management system. In [4] is discussed creating of such a system. The key part is to detect main processes in the company, the flow of business data and main decisions made upon these data. When creating decision mangement system we take into account several areas which are listed in following subsections.

\section{A. Repeated actions}

In observed data we take also accounting or human resources processes. The last mentioned processes usually use human actions for decision making in spite of that they can be formalized and the decisions can be made automatically. So if we identity tasks which are repeatedly executed we might take this part of process and describe it by using business rule, for example:

- If the total price of the order is min. CZK 1000 , shipping is free. 
As it was mentioned above. Another example of determination of salary id given on Figure 3.

\section{B. Transparency}

Another important point is to keep the set of rules open to changes. With the approach of formal grammar rules is the fulfilling of this condition quite easy. We may add or remove the rules according to the changes of organizations decision making. Change can be done in real time or nearly in real time. This characteristic ensures the transparency of maintaining of the business rules set. The transparency of the decision management system also lies in the understanding of using the created rules, so it is clear how each decision was made. The final set of rules must be clear to understand to all participants involved in the business processes. For this purpose serves created United dictionary of given organization.

Not all of decisions can be made without human decision, some processes requires human interaction, for example in cases when we need additional decisions. In this case the decision management guide and support the decision maker by restricting the available options or by focusing them on a specific set of information, which will be useful to making the final determination.

\section{Analysis on data and predictions}

Additional decisions can be added to system and it can predict future bahaviour according to the patterns which can be found in historical data. Pattern If something then do something else was previously mentioned in chapter IV., part B. But there is a number of other recognized patterns eg. strategic or incremental patterns.

Patterns can predict the most likely expected behaviour and thus can help with decision making. Patterns are useful when detecting anomalies in normal behaviour - eg. fraud detection, risk detection, opportunity detection. Detection of anomalies can't be made for sure in all cases, but it is always better to watch out for the fraud then to react to it after it is done.

In comparison with traditional approach, decision management systems stores data to improve the results by running analysis on historical data or learning and testing on sets of historical data.

Information in this section was based on [4] and [5].

\section{vi. Future development}

In the future we would like to focus on formalization of business rules using other systems than are Grammar systems. In this case, we like for example Programmed Grammars, that have success and failure sets of rules. We would like to focus also on other groups of business rules.

In overall, we would like to implement a system that would provide models of grammar systems for several basic types of business rules. These rules may simulate.

\section{Acknowledgment}

This work was partially supported by the BUT FIT grant FIT-S-14-2299, "Research and application of advanced methods in ICT".

\section{References}

[1] Csuhaj-Varjú, E., Vaszil, G. Theoretical computer science research group. An annotated bibliography of Grammar Systems [online]. [cit. 2015-02-14]. Available at

<http://www.sztaki.hu/mms/bib.html>

[2] Rozenberg, G., Salomaa, A. (editors). Handbook of formal languages Vol. 2 Linear Modeling: Background and application. Berlin: Springer, (C1997. ISBN 3- 540-60648-3, str. 528.

[3] Von Halle, B. The business rule revolution: running business the right way. Cupertino, CA: Happy About, (C2006. ISBN 978-160005-013-8, $291 \mathrm{~s}$.

[4] Taylor, J. Decision management systems: A practical guide to using business rules and predictive analytics. Upper Saddle River, NJ: IBM Press, C2012, Information management. ISBN 978-013-288438-9.

[5] Debevoise, T. Business Process Management with a Business Rules Approach: Implementing, The Service Oriented Architecture, Canada: Business Knowledge Architects, (C2005. ISBN 978-1419673689.

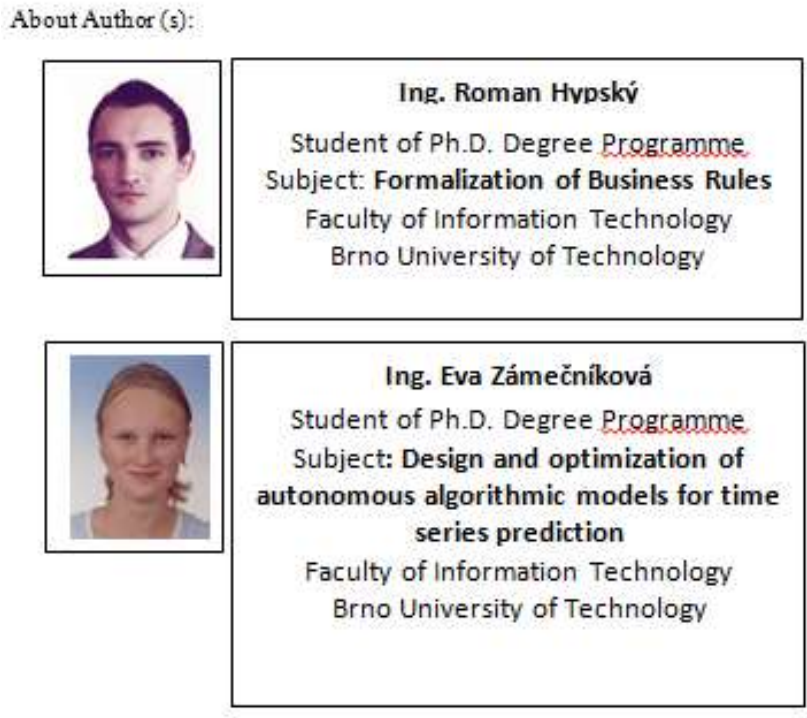

